\title{
O Ensino da Semiologia nas Escolas Médicas do Estado do Rio de Janeiro
}

\author{
Teaching the Medical Semiology at Medical \\ Schools in the State of Rio de Janeiro
}

Claudia M. de Vasconcellos Midão ${ }^{I}$ Lidia Ruiz-Moreno ${ }^{I I}$

\section{PALAVRAS-CHAVE \\ - Educação em Saúde. \\ - Educação Médica. \\ - Anamnese. \\ - Sinais e Sintomas.}

Recebido em: 14/07/2009

Reencaminhado em: 09/12/2009

Aprovado em: 21/01/2010
REVISTA BRASILEIRA DE EDUCAÇÃO MÉDICA $3 9 7 \longdiv { 3 4 ( 3 ) : 3 9 7 - 4 0 5 ; 2 0 1 0 }$

\begin{abstract}
RESUMO
Com o objetivo de caracterizar o ensino da Semiologia Médica no Estado do Rio de Janeiro, pesquisamos 14 cursos de graduação, sendo 11 privados e 3 públicos. Mediante abordagem quantitativa e qualitativa, os dados foram obtidos por meio de análise documental dos programas de ensino, aplicação de formulário e entrevista aos coordenadores das disciplinas. Foi observada semelhança entre os objetivos e conteúdos de Semiologia das diferentes escolas de Medicina, apesar de existir diversificação na denominação, inserção curricular e carga horária. As estratégias de ensino-aprendizagem, os recursos didáticos e a avaliação também mostraram especificidade segundo a instituição. A falta de padronização do ensino prático da Semiotécnica foi considerada uma das principais dificuldades, assim como a escassa disponibilidade de cenários de aprendizagem e de integração entre docência, assistência e pesquisa.
\end{abstract}

\section{ABSTRACT}

In order to describe the teaching of the Medical Semiology the State of Rio de Janeiro, we studied 14 undergraduate medical courses (11 private and 3 public). Using a quantitative and qualitative approach, data were obtained through document analysis of teaching programs, application of a form, and interviews with course coordinators. The objectives and contents of the Medical Semiology were similar between different medical schools, although they adopted different names, positions in the curriculum, and course load. The teaching-learning strategies, didactic resources, and grading or evaluation were also specific to each institution. One of the main difficulties was lack of standardization of practical teaching in basic clinical skills like medical interviews and physical examination, along with the lack of available learning scenarios and lack of integration between teaching, patient care, and research. 


\section{INTRODUÇÃO}

"O tratamento de uma doença pode ser inteiramente impessoal; o manejo de um paciente é obrigatoriamente pessoal."

F. PEABODY

As atuais Diretrizes Curriculares para o ensino da medicina constituem um avanço na construção coletiva de uma compreensão ampliada do processo saúde-doença, visando à adequação da formação profissional às necessidades dos serviços de saúde no Brasil. No tocante às competências, este documento estabelece que o futuro médico precisa desenvolver: "compreensão e domínio da propedêutica médica [...], capacidade reflexiva e compreensão ética e humanística da relação médico-paciente" ${ }^{\prime 1}$ (Art. 6º, item IV), como também capacidade de "comunicar-se com os colegas de trabalho, os pacientes e os familiares" ${ }^{\prime 1}$ (Art. $4^{\circ}$., item III). Existe consenso nas escolas médicas brasileiras sobre a necessidade de reformulação curricular. Porém, as Instituições de Ensino Superior (IES) se encontram em diferentes fases de implementação das mudanças, no sentido de oferecer à sociedade brasileira profissionais comprometidos com as necessidades de saúde da população².

No novo modelo proposto, o médico passaria de um técnico em órgãos e sistemas para um mediador de saberes ${ }^{3}$, um intérprete com proficiência em linguagens diversas, como as da ciência biomédica, psicologia e ciências sociais, que aprenderia constantemente a linguagem daqueles a quem atende, de modo a se comunicar com sua clientela adequadamente. Dentro deste paradigma, é importante a reformulação dos currículos das escolas médicas para privilegiar o desenvolvimento de competências necessárias para atender os atuais desafios, as quais envolvem não só habilidades técnicas, mas também aspectos atitudinais e éticos.

Semiologia - ou, mais propriamente, semeyologia — se origina do grego semeyion: sinal e logos: discurso, que significa estudo dos sinais. Segundo Hahmad e Valdes ${ }^{4}$, a palavra semiologia significa tratado, sinal ou semiótica; é o capítulo da patologia geral que se ocupa do estudo dos sinais e sintomas das enfermidades; é o ramo da ciência médica que ensina a técnica correta para obter sinais ou sintomas de determinado estado patológico mediante inspeção, palpação, percussão e ausculta.

O bom clínico, como todo bom médico, sabe fazer bom uso de sua visão, de sua audição, do seu olfato e de suas mãos, para observar, ouvir e auscultar, farejar, palpar e percutir o paciente. Conclui-se que, para ser um bom médico, é necessário também ser um bom semiota, ou seja, um bom identificador de sintomas ${ }^{5}$
A observação do modelo da história natural das doenças revela que a Semiologia intervém a partir do momento em que sinais e sintomas se fazem presentes. Esta intervenção acontece de forma predominante sobre a dimensão biológica da doença, negligenciando as dimensões psicológica e social. Constata-se uma pobreza no desenvolvimento de novos instrumentos que possam enriquecer a Semiologia em suas dimensões psicológica e social, ao mesmo tempo em que se presencia a incorporação pouco crítica de recursos tecnológicos desenvolvidos para contemplar a dimensão biológica das doenças.

Mestre de Semiologia e professor da Jonhs Hopkins University e de outras universidades dos Estados Unidos, William Osler destacou-se no ensino da medicina, chamando a atenção para a importância da história clínica e da Semiologia no raciocínio clínico.

Devido à relevância da Semiologia na formação médica e à necessidade de ampliar os espaços de troca de saberes e experiências sobre o ensino médico, o objetivo do presente trabalho foi caracterizar o ensino da Semiologia nas escolas médicas do Estado do Rio de Janeiro, focalizando sua inserção curricular, objetivos de aprendizagem, conteúdos programáticos, estratégias de ensino-aprendizagem e práticas de avaliação.

\section{MÉTODOS}

Este estudo apresenta parte dos resultados de dissertação de mestrado que pesquisou 14 escolas de Medicina no Estado do Rio de Janeiro, sendo 11 privadas e 3 públicas. Os sujeitos da pesquisa foram os 18 coordenadores/responsáveis pelas disciplinas de Semiologia Médica, pois em uma das escolas a disciplina é subdividida em três, e em outras duas escolas é subdividida em duas, tendo cada uma delas um coordenador responsável. Os coordenadores, que mostraram excelente receptividade para participar da pesquisa, foram escolhidos como parceiros por considerarmos que são os articuladores do processo de ensino-aprendizagem de Semiologia, envolvidos com as facilidades e dificuldades da condução e planejamento das propostas de ensino-aprendizagem e avaliação. Além disso, são sujeitos-chave na dinâmica da instituição, uma vez que se relacionam com o corpo docente, discente e gestão administrativa. Para garantir o sigilo das informações, os coordenadores são referidos como C1 a C18.

Para a coleta de dados foi realizada, numa primeira aproximação, a análise documental dos programas, ementas e planos de ensino de Semiologia, assim como dos currículos e propostas curriculares de cada instituição, denominados no presente trabalho como EM1 a EM14. O destaque foi 


\section{GRÁFICO 1}

Percentual de carga horária de Semiologia em relação à carga horária total do curso de Medicina das escolas médicas do Estado do Rio de Janeiro

\section{Carga Horária Percentual de Semiologia}

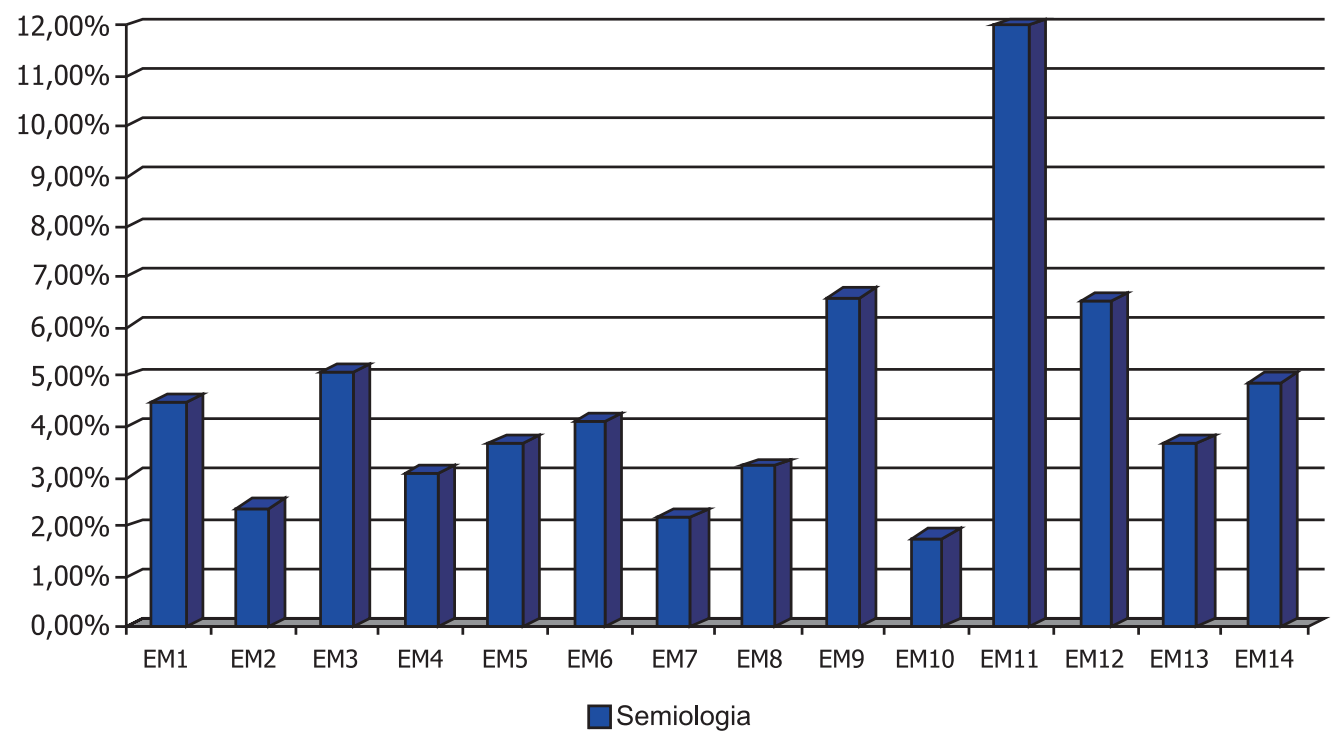

dado aos itens objetivos, conteúdos programáticos, estratégias de ensino-aprendizagem e avaliação. Numa segunda etapa, a coleta de dados compreendeu a aplicação de formulário e entrevista semiestruturada aos coordenadores, o que permitiu a triangulação de informações. Os roteiros de entrevista e do formulário foram aprimorados e adequados mediante estudo piloto com o coordenador de uma das escolas médicas e satisfeitos todos os procedimentos previstos pelo Comitê de Ética da Universidade Federal de São Paulo.

O formulário permitiu a obtenção de dados sobre distribuição da carga horária destinada à Semiologia, estratégias e cenários de ensino-aprendizagem, recursos didáticos e avaliação. Já a entrevista focalizou, além dos aspectos referidos, a integração da Semiologia com outras disciplinas, facilidades e dificuldades do ensino da disciplina. Os dados obtidos através dos formulários e dos documentos institucionais foram analisados mediante leitura e releitura exaustivas. As entrevistas gravadas foram transcritas integralmente e realizada análise temática ${ }^{6}$.

\section{RESULTADOS E DISCUSSÃO}

A Semiologia é uma disciplina obrigatória nas 14 escolas médicas estudadas, mas com diferentes denominações: Clínica Propedêutica Médica I e II, Diagnóstico Clínico, Clínica Médica da Criança e do Adolescente e Clínica Médica do Adulto e do
Idoso, Semiologia I e II, Medicina Interna, Propedêutica Médica I e II, Clínica Propedêutica Médica I, Propedêutica Médica, Bases do Diagnóstico Clínico, Semiologia Médica, Semiologia, Semiologia e Semiotécnica, Clínica Médica e Propedêutica I e Propedêutica Médica.

Existe também grande variação no momento de sua inserção curricular. Das 14 escolas estudadas, 6 (43\%) oferecem a Semiologia nos $5^{\circ}$ e $6^{\circ}$ semestres, 3 (22\%) nos $4^{\circ}$ e $5^{\circ}$ semestres, $2(14 \%)$ no $5^{\mathrm{o}}$ semestre, 1 (7\%) no $4^{\mathrm{o}}$ semestre, 1 (7\%) nos $3^{\mathrm{o}}$ e $4^{\circ}$ semestres, e $1(7 \%)$ nos $1^{\circ}$, $4^{\circ}$ e $5^{\circ}$ semestres. A inclusão do ensino de Semiologia já no primeiro ano, adotada por uma das escolas, pode facilitar a integração vertical e horizontal do currículo.

A carga horária total da disciplina varia significativamente nos diversos cursos médicos estudados, já que oscila entre 168 a 680 horas, de modo que as horas destinadas ao ensino de Semiologia representam entre 1,8\% e 12\% da carga horária total do curso (Gráfico 1). A carga horária semanal da Semiologia varia de 4 a 28 horas.

Apenas um dos cursos estudados apresenta uma grade curricular estruturada na metodologia de Aprendizagem Baseada em Problemas (ABP), sendo que a maioria das escolas médicas pesquisadas adota uma organização disciplinar tradicional em seus currículos. Entretanto, existem diferentes movimentos institucionais, no sentido de avançar na abordagem 
interdisciplinar. Numa das escolas, o coordenador de Semiologia participa da confecção dos programas de algumas disciplinas do ciclo básico, como Fisiologia, Biofísica e Bioquímica, com o propósito de articular o conteúdo programático do ciclo básico com o profissional. Em outras escolas, os coordenadores da Semiologia realizam atividades conjuntas com outras disciplinas e com outros cursos da área da saúde, visando à: "Integração com a radiologia, com a pediatria, com a psicologia médica, a cirurgia experimental, com saúde mental (psiquiatria) $[\ldots]^{\prime \prime}$ (C3)

A tentativa de uma abordagem interdisciplinar e multiprofissional, preconizada no documento das Diretrizes Curriculares, manifesta-se também por meio da participação de professores de outras disciplinas em aulas de Semiologia, com o objetivo de abordar os conteúdos sob diferentes perspectivas. $\mathrm{O}$ atual movimento de mudança curricular também inclui a inserção, o mais cedo possível, do aluno na comunidade. Tal procedimento propicia a articulação da Semiologia com outras disciplinas no cenário de atenção básica do Sistema Único de Saúde (SUS).

Para a análise dos objetivos de aprendizagem e conteúdos programáticos, nos baseamos na classificação proposta por Bloom ${ }^{7,8}$, que compreende três dimensões: cognitiva, procedimental/habilidades e afetivo/atitudinal. Todos os programas de ensino analisados abrangem essas três dimensões, mas com ênfase nos aspectos cognitivos e procedimentais. Estes últimos se referem à coleta de anamnese, realização de exame físico e redação dos achados obtidos na entrevista e durante o exame médico.

A comunicação, escrita e verbal, para o desenvolvimento de habilidades específicas da Semiologia Médica é considerada importante pelos coordenadores entrevistados. Todavia, somente o programa de ensino de uma disciplina valoriza a comunicação como meio para o aluno se expressar. "Expressar-se de maneira verbal e escrita de maneira objetiva e coerente." (EM). "Sustentar suas opiniões em discussões de equipe." (EM9)

Objetivos sobre a dimensão atitudinal/afetiva, na totalidade dos documentos analisados, são atribuídos, primordialmente, à relação médico-paciente e à inserção do aluno em novos cenários de aprendizagem. Conteúdos programáticos focados nesta dimensão não são valorizados nos planos de ensino. A visão do paciente de forma integral e os aspectos éticos que norteiam o exercício médico são explicitados em apenas $14,3 \%$ dos programas de Semiologia.

A triangulação dos dados coletados, realizada neste estudo, nos permitiu constatar a distância entre o teor dos programas de ensino analisados, em que persiste uma visão tradicional do ensino médico, e as informações obtidas durante as entrevistas, nas quais os coordenadores explicitam, com clareza, a importância de aspectos relacionados à dimensão atitudinal a serem desenvolvidos pelo estudante de Medicina, especialmente os referentes a contato com o paciente e familiares, atuação em equipe multiprofissional, inserção no ambiente hospitalar e aproximação com uma realidade socioeconômica e cultural muito distante do cotidiano dos estudantes. Seriam estas experiências as responsáveis pelo amadurecimento e mudança de postura dos alunos, observados pelos coordenadores ao longo da disciplina.

Para mim, a Semiologia é a grande mãe da medicina, [...] eu queria fazer essa ressalva e [...] ela está sendo obscurecida em detrimento de avanços tecnológicos cujo interesse não é para melhoria do paciente, são avanços relacionados a questões de indústrias [...], então assim, saber ouvir o paciente, saber se comunicar com o paciente, porque não basta eu ouvir e entender, ele também tem que entender o que estou falando para ele. (C9)

“[...] a Semiologia é fantástica, mas ela é uma das disciplinas que mais lida com o doente, muitas vezes falando sobre coisas que ele não gostaria de falar, falando sobre sexualidade, a vida afetiva dele [...]" (C10).

"Fundamental, você tem que aprender bem o que é uma anamnese, a arte de saber ouvir, a arte de examinar, porque baseado nisso, com certeza você já é capaz de diagnosticar [...], então eu acho que é a base e sem uma boa base você não vai para frente" (C5).

"[...] porque a Semiologia é a base da medicina, é o alicerce do curso médico, e o aluno vê isso, sente isso, é na Semiologia que ele vai aprender as ferramentas para exercer a profissão que ele quer" (C14).

“Agora vocês vão começar a aprender a ser médicos de verdade, eu acho que é muito importante, [...], quando eles chegam no quinto período, eu até brinco com eles e digo: olha, vocês nunca mais serão os mesmos" (C5).

Dentre as estratégias de ensino-aprendizagem, as aulas práticas ocupam o maior percentual de carga horária de Semiologia, o que coincide com a relevância, sinalizada nos programas de ensino, dos objetivos e conteúdos programáticos referidos à dimensão procedimental (Gráfico 2).

Embora os objetivos e conteúdos programáticos de Semiologia sejam muito semelhantes entre os diferentes cursos médicos, alguns coordenadores, durante as entrevistas, afirmaram que a heterogeneidade do corpo docente leva à falta 


\section{GRÁFICO 2}

Distribuição da carga horária total da disciplina de Semiologia em relação às atividades teóricas, práticas e teórico-práticas nas escolas médicas do Estado do Rio de Janeiro

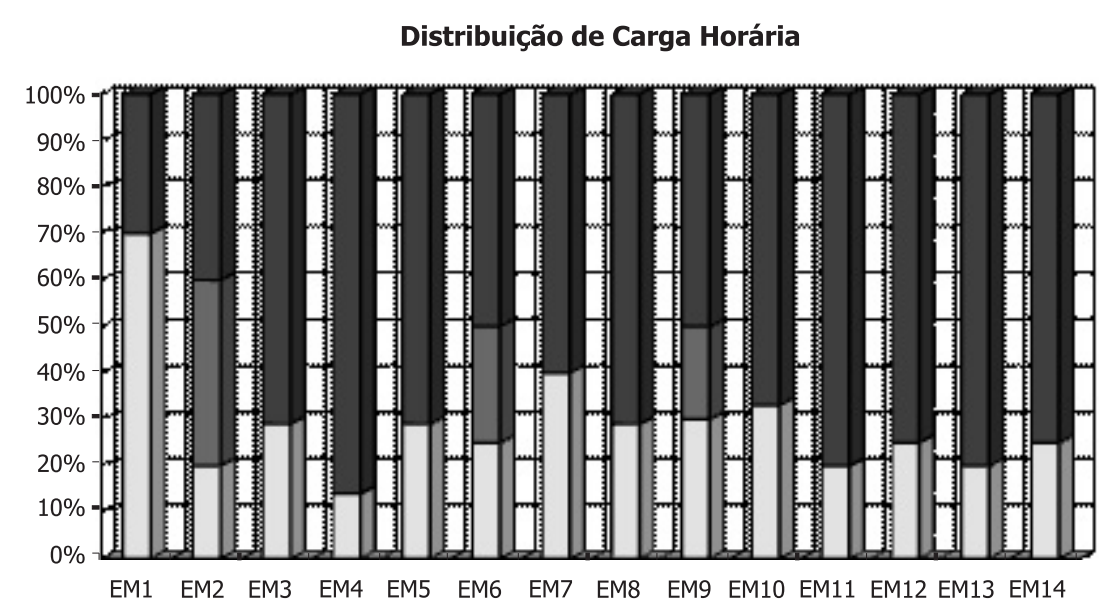

Teórica

Teórico-prática

Prática

de uniformidade nas estratégias de ensino-aprendizagem, especialmente nas atividades práticas.

A gente trabalha com vários professores que têm perfis diferentes, que vêm de escolas diferentes, aprenderam semiologias diferentes, não é fácil conseguir um grupo uniforme; então a dificuldade é essa, é a heterogeneidade, temos que dar importância ao método, para o aluno ter uma sequência do que ele tem que fazer, para não se perder. (C14)

Entre as atividades teóricas, a aula expositiva tradicional é a estratégia didática mais utilizada para abordagem dos aspectos cognitivos. Somente um curso aboliu as aulas expositivas, substituindo-as por seminários. A introdução à pesquisa científica, como estratégia didática, é explicitada somente por duas escolas. Em relação aos recursos didáticos, todos os entrevistados usam: quadro de giz e/ou branco, transparências, diapositivos, projetor multimídia, vídeos, fitas de áudio e CD-ROM com tópicos médicos, além da internet.

Apesar da definição das estratégias nos programas de ensino, que incluem a descrição das atividades a serem desenvolvidas em relação aos aspectos cognitivos, a maioria dos programas não explicita as estratégias didáticas a serem realizadas nas dimensões atitudinal e das habilidades.

Esta lacuna, presente na maioria dos programas, pode explicar, em parte, a heterogeneidade de abordagens e a escassez de critérios comuns entre os diversos docentes para desenvolver conteúdos no que se refere ao aprendizado sistematizado da relação médico-paciente e a aspectos éticos. Isto é apontado pelos coordenadores como uma das principais dificuldades para o ensino da Semiologia.

Em consonância com o atual momento de mudanças na educação médica, as propostas programáticas analisadas evidenciam uma tendência à diversificação de estratégias didáticas - seminários, aulas dialogadas, discussões nas aulas teóricas, casos clínicos, fórum interdisciplinar, estudo de situações-problema - que pressupõem maior participação do aluno no processo de construção de conhecimentos, promovendo o uso de bibliotecas e o desenvolvimento de pesquisa bibliográfica.

Nem todas as instituições oferecem as condições necessárias à inserção do docente nas atividades de pesquisa, e raramente a área da Semiologia é foco de trabalhos científicos. Tal fato gera falta de enriquecimento do aprendizado e ausência de modelo de pesquisador para os alunos ${ }^{9}$.

$\mathrm{Na}$ visão de dois entrevistados, o desenvolvimento de linhas de pesquisa nesta área atuaria como facilitador do ensino da Semiologia: "E outro facilitador seria fazer da propedêutica, do ensino da propedêutica uma linha de pesquisa. Aqui não tem isso" (C1). "[...] fazer da propedêutica, do ensino da propedêutica uma linha de pesquisa [...]" (C2).

Como sustenta Maia ${ }^{10}$, metodologias de ensino se baseiam na transmissão de informações e na centralidade docente em 
aulas expositivas, com reduzidos recursos didáticos complementares, sendo que a busca ativa de informações não é adequadamente estimulada.

A baixa frequência na utilização de estratégias que promovam a aprendizagem significativa pode ser explicada pela escassa participação dos professores em processos de formação docente, aspecto destacado pelos coordenadores como uma dificuldade para o ensino de Semiologia. Na visão da maioria dos coordenadores: "[...] é preciso um maior número de docentes, eu acho que é preciso um estímulo maior à capacitação do docente [...]" (C8).

Os cenários de ensino-aprendizagem correspondem a enfermarias e/ou ambulatórios de hospitais universitários, de ensino e conveniados. Uma das disciplinas visita serviços de emergência; outra, postos de saúde do município; e uma terceira, escolas do ensino fundamental e comunidade, por meio de mutirões. Além das bibliotecas, algumas escolas já incluem em seus cenários os laboratórios de habilidades e multimídia.

Em duas escolas onde os alunos só entram em contato com pacientes ambulatoriais, os coordenadores comentaram a necessidade de ampliar os ambientes de inserção: "[...] o hospital é a única coisa que está faltando para a gente [...]" (C5). "[...] precisamos é levar o aluno mais para a enfermaria, para ele poder colher mais anamnese e fazer mais exames físicos" (C4).

Fraga Filho ${ }^{11}$ afirma que a tônica da educação médica deve ser o binômio ensino-serviço. Assim, os cenários de aprendizagem utilizados para o ensino-aprendizagem de Semiologia mostram grande diversidade de serviços assistenciais. Esta perspectiva é compartilhada por um dos coordenadores que desenvolve um projeto de inserção dos alunos nas unidades básicas de saúde (UBS): “[...] eu acredito que os cenários da unidade básica vão ser uma grande facilidade para a Semiologia, pelo contato maior com pacientes saudáveis" (C9).

Para que ocorra uma formação profissional e o desenvolvimento de competências previstas no documento das Diretrizes Curriculares, é imprescindível que haja uma interação entre escola, comunidade e serviços de saúde, mediante parcerias que possibilitem tal processo ${ }^{10}$. Neste sentido, os coordenadores participantes desta pesquisa valorizam a diversificação de cenários de aprendizagem e o contato dos alunos com diversos setores comunitários: "[...] é a criação da Unat — Universidade Aberta para a Terceira Idade - que nós temos aqui, nós temos trezentos e poucos idosos inscritos, a Semiologia participa ativamente não só no exame físico, mas no acompanhamento deles" (C6). "Existe na universidade o programa de saúde da família. [O aluno] está diretamente inserido na comunidade, eles fazem visita domiciliar" (C13).
Alguns coordenadores, ao comentarem a inserção no SUS, disseram que não basta a entrada do aluno na UBS; deve existir também a preocupação com a adequação do ensino da disciplina e o compromisso com a aprendizagem do aluno. Eles destacaram a importância da presença do preceptor:

[...] eu acho que a gente tem que melhorar a construção desses objetivos educacionais nas unidades básicas, na comunidade. Tem que identificar em cada comunidade um preceptor para esses alunos [...] eu queria que o aluno tivesse mais contato com o agente comunitário nesse momento. (C9)

Entretanto, a necessidade de ampliar a inserção dos alunos no SUS não é consenso entre os coordenadores de Semiologia. Alguns deles questionam a utilidade de inserir os alunos no nível primário de atendimento, considerando a realidade do sistema de saúde local: "Não acredito no ensino da Semiologia, também em nível primário, acho difícil, pelo menos nessa estrutura de saúde que temos no município do Rio de Janeiro, que é o médico atendendo 16 doentes em 4 horas, mas a gente sabe que o médico entra e sai correndo, exame físico é rapidinho [...]" (C11).

Nesse momento não dá para você ensinar a Semiologia no SUS com a estrutura que a gente tem, seria um bom cenário, mas nesse momento é impossível. A gente realmente precisa de um nível secundário e terciário porque tem pacientes com patologias [...], enfim, o doente está internado, então para a Semiologia um nível secundário ou terciário até é bom [...] (C11)

“Eu acho que a Semiologia não ajuda na questão do SUS, porque na realidade o raciocínio, aqui, é de um hospital, de atendimento secundário e terciário" (C11).

Outros coordenadores participantes consideram que os alunos, provenientes de uma classe socioeconômica diferenciada, não estão preparados para o contato com a realidade da maioria da população. Assim, muitos coordenadores não veem, no momento, relação entre a Semiologia e o SUS:

Eu acho que o dia a dia de um hospital público, de qualquer entidade pública onde você atende o doente, para alguns alunos é a primeira vez que eles têm contato com a pobreza, miséria e fome, e a gente percebe que eles não estão preparados para isso. Desconhecem completamente que no país onde eles moram existe fome, miséria e pobreza. (C13)

O debate sobre a entrada do aluno em diferentes ambientes e níveis de atenção está presente nas escolas médicas. Um 
dos coordenadores entrevistados comenta a importância da inserção do aluno nas UBS e considera que o contato com a realidade do sistema de saúde proporciona um espaço de reflexão sobre os aspectos socioeconômicos da população e os entraves relacionados à organização e operacionalização do SUS, pois constituem aspectos importantes na compreensão dos múltiplos determinantes do processo de saúde-doença para o futuro profissional, nem sempre consciente dos problemas que afetam a maioria da população: "A psicologia médica tenta chamar essa atenção para a realidade do País, porque, como eles não gostam de ver, eles não leem jornal [...]" (C13).

“O aluno acaba vivenciando os problemas que o SUS tem [...] aquele paciente que não tem tratamento adequado, [...] a dificuldade de conseguir alguns exames complementares, o tempo de demora [...]" (C3).

"[...] eles já começam a ver como funciona essa burocracia [do SUS], tem que marcar ambulatório, ele [paciente] não vai ter dinheiro para a passagem do ônibus para ir marcar, então tem que mandar um agente da comunidade ir nas casas para marcar para todo mundo [...] porque o SUS não paga o exame, a prefeitura não paga, então eles já começam a perceber." (C5)

Estamos de acordo com Almeida et al. ${ }^{12}$ quando afirma que a experiência obtida até o momento mostra ser possível ensinar Semiologia fora do ambiente hospitalar, pois as dificuldades para essa prática são bem menores do que pareciam a princípio.

Alguns coordenadores questionam a inserção dos alunos no nível primário de atendimento, em função da dificuldade de supervisão docente nessas unidades. Outra dificuldade comentada pelos sujeitos da pesquisa é que a sobrecarga de atividades assistenciais e as precárias condições de trabalho prejudicam o processo de ensino-aprendizagem, na visão dos coordenadores.

A participação dos pacientes nestes cenários apresenta diversidade também para o ensino de Semiologia nas diversas escolas médicas. Para um dos coordenadores, as aulas práticas com pacientes permitem melhor integração conceitual: "Acho que a facilidade que a gente tem é muito paciente [...], eles [alunos] vivenciam uma prática daquilo que eles estão aprendendo na teoria [...]" (C5).

Em pelo menos duas instituições, a limitação do número de pacientes foi apontada como uma dificuldade para a realização das atividades práticas: "[...] redução no número de leitos do hospital e com isso os pacientes ficam sendo assediados pelos alunos e cada vez menos tolerantes à abordagem [...]" (C2). "A limitação dos pacientes hospitalizados [...] a gente pega paciente já com patologia avançada, complicada [...]" (C8).

Indagados sobre o papel do paciente nos diversos cenários do ensino de Semiologia, a maioria dos coordenadores enfatizou a importância de considerá-lo um sujeito fundamental para o desenvolvimento das competências técnicas e humanas do futuro profissional: "Acho que o mais importante é o interesse pelo paciente, é fundamental" (C6).

Entretanto, na fala de alguns coordenadores, é possível perceber uma visão utilitária e parcial da relação do aluno com o paciente, considerando-o um objeto e tendo o foco de atenção voltado para o quadro clínico: "Tem que explorar o paciente, no sentido de mostrar tudo que é possível da história. Tentar correlacionar. Ver o prontuário junto com o aluno [...]" (C3). "[...] eu acho que uma das dificuldades que eu tenho é que nem sempre tenho o número de pacientes que gostaria de ter, nem sempre tenho as patologias que gostaria de ter para mostrar aos alunos [...]" (C10).

Este modelo docente leva o aluno também a "coisificar" o paciente, subordinando-o a uma relação de uso evidente ${ }^{13}$. Este modelo de prática desenvolve uma relação sujeito-objeto, na qual o médico-sujeito, encarregado de executar a ação, dirige seu ato ao doente-objeto, sem opinião e sem vontade. $\mathrm{O}$ momento atual, o movimento mundial e as diretrizes curriculares impõem a necessidade de uma relação sujeito-sujeito ${ }^{14,15}$.

Concordando com Gonçalves ${ }^{15}$, entendemos que o paciente deve sempre ser visto como um ser biográfico, pois tem história própria e raciocina, tendo que ser visto como pessoa, o centro da educação e profissão médicas, já que o doente é a razão de ser da medicina, objeto das preocupações e da dedicação do médico.

Para realizar a avaliação da aprendizagem, os alunos de Semiologia fazem provas escritas relacionadas a aspectos cognitivos e provas orais geralmente relacionadas à dimensão procedimental, assim como avaliações contínuas do desempenho durante as aulas. A formatação da prova teórica é muito variável, e a prova prática é composta por coleta de anamnese e realização de exame físico, sob observação do professor. Somente num programa de ensino está caracterizada a avaliação formativa, embora alguns relatem que a modalidade formativa de avaliação acontece no cotidiano do ensino de Semiologia.

Uma escola introduziu o portfólio como instrumento de avaliação e para isso promoveu capacitação docente. Esta experiência foi aprovada por discentes e docentes, pois permitiu, na ótica dos coordenadores, a análise da aprendizagem cognitiva e do desenvolvimento de outras habilidades, além da autoavaliação. 
A avaliação é um processo complexo que só é democrático quando orientado para melhorar a compreensão do fenômeno educativo e a prática formativa ${ }^{16}$. Concordamos com a afirmação de Seiffert e Abdalla ${ }^{17}$ de que a avaliação deve ser não somente somativa, isto é, voltada para a análise de resultados terminais, mas também formativa, com o objetivo de permitir ações de intervenção durante o período letivo da disciplina.

A falta de formação pedagógica dos docentes adiciona grandes dificuldades ao processo avaliativo da aprendizagem, porque, na maioria das vezes, os professores continuam a realizar somente avaliações somativas, com caráter punitivo, sem preocupação com a retroalimentação do processo ensino-aprendizagem-avaliação.

$\mathrm{O}$ ato de avaliar não se destina a um julgamento definitivo sobre alguma coisa, pessoa ou situação, pois não é ato seletivo. A avaliação se destina ao diagnóstico e, por isso mesmo, à inclusão ${ }^{18}$.

\section{CONCLUSÕES}

O ensino de Semiologia apresenta grande variação de carga horária nas diferentes escolas médicas do Rio de Janeiro, com forte predomínio de aulas práticas para o ensino dos conteúdos procedimentais, especialmente os referidos à anamnese e ao exame físico de pacientes. Embora haja predomínio de atividades práticas no ensino da Semiologia, existe grande heterogeneidade nas técnicas utilizadas para o treinamento do exame físico, principalmente devido à diversidade de professores procedentes de diferentes escolas, à alta rotatividade do corpo de professores e à escassa formação docente.

Há predomínio de aulas expositivas para abordar conteúdos teóricos e avaliação somativa para verificar a retenção de conhecimentos, sem compromisso com devolutiva aos alunos sobre o processo de ensino-aprendizagem. A avaliação da aprendizagem foi considerada o aspecto mais complexo do processo educativo, devido à falta de formação pedagógica para aprimorar estas práticas.

Os programas de ensino analisados não explicitam ações para desenvolvimento de atitudes éticas e humanização das relações interpessoais, apesar de se tratar de uma disciplina que atua diretamente em contato com pacientes e familiares.

Nos últimos anos, houve crescente diversidade de cenários de ensino-aprendizagem nas escolas médicas do Rio de Janeiro, em consonância com a implantação do SUS, embora a inserção dos alunos no sistema constitua um aspecto polêmico.

\section{REFERÊNCIAS}

1. Ministério da Educação. Conselho Nacional de Educação. Câmara de Educação Superior. Resolução CNE/CES nº4 de 7 de novembro de 2001. Institui diretrizes curriculares nacionais do curso de graduação em Medicina. Diário Oficial da União. Brasília, 9 nov. 2001; Seção 1, p.38.

2. Aguiar AC, Cordeiro HA. Integração Vertical e Horizontal do Currículo Médico no Contexto das Novas Diretrizes Curriculares: O Curso de Medicina da Universidade Estácio de Sá. Rev Bras Educ Med. 2004;28(2):164-72.

3. Ribeiro EC. O trabalho docente em transformação: bases para conformação de um programa de desenvolvimento docente na medicina. Caderno LCE. 1999;1:25-33.

4. Hahmad AD, Valdes JA. Anamnesis: um instrumento olvidado de la semiologia médica. Med Interna Méx. 2000;16(3):132-8.

5. Surós J. Semiologia Médica e Técnica Exploratória. $6^{\mathbf{a}}$ ed. México: Salvat Mexicana de Ediciones; 1984.

6. Minayo MCS. O Desafio do Conhecimento: pesquisa qualitativa em saúde. 8aa ed. São Paulo: Hucitec; 2004.

7. Bloom BS, Engelhart MD, Furst EJ, Hill WHj, Krathwohl DR. Taxonomia de Objetivos Educacionais: compêndio primeiro: domínio cognitivo. Porto Alegre: Globo; 1979.

8. Bloom BS, Krathwohl DR, Masia BB. Taxonomia de Objetivos Educacionais: domínio afetivo. Porto Alegre: Globo; 1976.

9. Bordenave JD, Pereira AM. Estratégias de Ensino-Aprendizagem. 25a ed. Petrópolis: Vozes; 2004.

10. Maia JA. O Currículo no Ensino Superior em Saúde. In: Batista SH, Batista NA, orgs Docência em saúde: temas e experiências. São Paulo: Senac; 2004. p.101-33

11. Fraga Filho C. Ensino médico no Brasil: análise crítica. Arq Gastroenterol. 1988;25(2):26-31.

12. Almeida CAN, Del Ciampo LA, Oliveira JED. Semiologia pediátrica: experiência de ensino e aprendizagem segundo uma nova proposta de curso médico. Pediatria (São Paulo). 2000; 22(1):10-3.

13. Sayd JD, Andrade DE, Silva MPDR. O aprendizado da semiologia em um currículo tradicional. Rev Bras Educ Med. 2003;27(2):104-13.

14. Gonçalves EL. De Ingressante na Faculdade A Médico Especialista: Uma Longa Trajetória. In: Marcondes E, Gonçalves EL, orgs. Educação Médica. São Paulo: Sarvier; 1998. p.325-39.

15. Gonçalves EL. O Ensino Médico, Pré-Figuração do Exercício Profissional. Rev Hosp Univ. 2001;11(1/2):44-51.

16. Sobrinho JD. Avaliação: políticas, educacionais e reformas da educação superior. São Paulo: Cortez; 2003.

17. Seiffert OMLB, Abdalla IG. Avaliação Educacional na Formação Docente para o Ensino Superior em Saúde. In: Batista SH, Batista NA, orgs. Docência em saúde: temas e experiências. São Paulo: Senac; 2004. p. 167-85. 
18. Luckesi C, Barreto E, Cosma J, Baptista, N. Fazer Universidade: uma proposta metodológica. São Paulo: Cortez; 2000 .

\section{CONTRIBUIÇÃO DOS AUTORES}

Ambas autoras participaram, de forma significativa, na elaboração do artigo

\section{CONFLITO DE INTERESSES}

Declarou não haver.

\section{ENDEREÇO PARA CORRESPONDÊNCIA}

Faculdade de Medicina de Petrópolis — Fase Claudia M. de Vasconcellos Midão

Av. Barão do Rio Branco, 1003

Centro - Petrópolis

CEP 25680-120 RJ

E-mail: claudiavasconcellos@fmpfase.edu.br 